\title{
Review: cognitive therapy has a beneficial effect equivalent to behaviour therapy and that of antidepressants in patients with mild to moderate depression
}

\author{
Gloaguen V,Cottraux J, Cucherat M, et al.A meta-analysis of the effects of cognitive therapy in depressed patients.J Affect Disord \\ 1998 Apr;49:59-72.
}

\section{Question}

In patients with mild to moderate depression, is cognitive therapy (CT) an effective treatment?

\section{Data sources}

Studies were identified by searching Medline and EMBASE/ Excerpta Medica; scanning the bibliographies of identified papers and books; referring to previous reviews; reviewing the abstracts from congress presentations; and preprints sent by authors.

\section{Study selection}

Studies were selected if they were randomised controlled trials with $\geqslant 1$ CT group and 1 comparison group (waiting list, placebo, antidepressants, behaviour therapy, or another psychotherapeutic treatment) in patients who had major depression or dysthymic disorder, with the exclusion of psychotic depression and bipolar affective disorder.

\section{Data extraction}

Data were extracted on patient characteristics, treatment conditions, and severity of depression after treatment measured using the Beck Depression Inventory (BDI).

\section{Main results}

78 trials were identified of which 48 , including 2765 patients, met the selection criteria. In the 20 studies that compared CT with waiting list or placebo, the average patient in the CT group was $29 \%$ better than the average patient in the control group after treatment (effect size 0.82, $\mathrm{p}<0.001$ ). In the 17 trials that compared CT with antidepressants, the average patient in the
CT group was $15 \%$ better than the average patient in the antidepressant group after treatment (effect size $0.38, \mathrm{p}<0.001$ ). In the 22 trials that compared CT with a group of miscellaneous therapies (including psychodynamic therapies, interpersonal therapies, non-directive, supportive, relaxation, and alternative bibliotherapy), the average patient in the CT group was $10 \%$ better than the average patient in the other therapies group after treatment (effect size $0.24, \mathrm{p}<0.01$ ). There was no significant heterogeneity* in the results of studies comparing CT $v$ antidepressants, or CT $v$ other therapies. In the 13 trials that compared CT with behaviour therapy, no difference existed between groups (effect size $0.05, \mathrm{p}=0.95$ ), but there was evidence of significant heterogeneity* between studies $(\mathrm{p}<0.001)$. In multiple regression analysis, after adjustment for type of treatment, no association was found between the effect size and BDI score, sex, and age. In the 8 trials that allowed a comparison of CT with antidepressants at 1 year follow up, 5 of the 8 studies suggested a preventive effect of CT on relapse rate.

\section{Conclusion}

In patients with mild to moderate depression, cognitive therapy has a beneficial effect equivalent to that of behaviour therapy and that of antidepressants and a group of other miscellaneous therapies.

*Heterogeneity means that there is greater variation in the results of the trials than would be expected by chance variation alone, and the pooled estimate must be interpreted with caution.

Source of funding: no external funding.

For correspondence:Dr J Cottraux, Anxiety Disorder Unit, Hopital Neurologique, 59 boulevard Pinel, 69394 Lyon, France. Fax +3372357330

Abstract and commentary also published in Evidence-Based Medicine.

\section{Commentary}

The conclusion about the efficacy of CT for depression is no longer tentative. For mild to moderate depression, it may even be the treatment of choice. Scientific evaluation of the effectiveness of different modes of treatment is welcome news for the clinician. This is especially meaningful when emerging conventional clinical wisdom is supported by research. Clinicians seem comfortable with the conclusion that for mild to moderate depression patients can be offered the choice of short term therapy (cognitive or behavioural) or medication. This review by Gloaguen $e t$ al supports those who believe that cognitive behavioural therapy should be the treatment of first choice for depression.

The comparison of CT with behaviour therapy and other psychotherapies leads the reader to the "specific, non-specific" factors debate of what is central to therapeutic change. ${ }^{2}$ This debate has recently been discussed by Oei and Shuttlewood in the area of CT for depression and remains a controversial issue. ${ }^{3}$ The suggestion that "cognitive modification" is the specific factor in the treatment of depression was not supported by the analysis by Gloaguen et al. This was attributed to the use of a number of similar strategies by both CT and behaviour therapy.

An additional point of interest in this review is the suggestion of a preventive effect of CT on relapse rate. The possibility that treating depression with CT or behaviour therapy may reduce the risk of relapse or perhaps the need for further treatment is considered by some to be one of the most exciting outcomes of research in this area because recurrence of depressive episodes is not uncommon after successful treatment. ${ }^{4}$

Anthony Bellissimo, MASc, $\mathrm{PhD}$ McMaster University Hamilton, Ontario, Canada

1 Antonuccio DO, Danton WG, De Nelsky GY. Psychotherapy versus medication for depression: challenging the conventional wisdom with data. Professional Psychology: Research and Practice 1995;26:574-85.

2 Frank JD, Frank JB. Persuasion and healing: a comparative study of psychotherapy ( ${ }^{\mathrm{rd}}$ edition) a comparative study of psychotherapy ( 3 edition)

3 Oei TPS, Shuttlewood GJ. Specific and nonspecific factors in psychotherapy: a case of cognitive therapy for depression. Clinical Psychology 1996;16:83-103

4 Teasdale JD. Assessing cognitive mediation of relapse prevention in recurrent mood disorders. Clinical Psychology and Psychotherapy 1997;4:145-56. 


\section{OTHER ARTICLES NOTED}

The journals that are reviewed and the criteria for selecting articles from these journals for inclusion in Evidence-Based Mental Health are set out in the purpose and procedure in each issue. All articles that meet our criteria in the reviewed journals are cited in Evidence-Based Mental Health, but there is not enough space to abstract them all. The following articles passed all criteria but were not abstracted because, in the judgment of the editors, their findings were less widely applicable to clinical practice in the area of mental health.

\section{Therapeutics}

Rehabilitation for traumatic brain injury. Chestnut RM, Carney N, Maynard H, et al. Evidence Report/Technology Assessment no 2. AHCPR publication no. 99-E006. Rockville, MD: Agency for Health Care Policy and Research. February 1999.

PTSD in ambulant RTA victims: a randomized controlled trial of debriefing. Conlon L, Fahy TJ, Conroy R. J Psychosom Res 1999 Jan;46:37-44.

SSRIs versus alternative antidepressants in depressive disorder. (Cochrane Review, latest version 16 Jul 1999). Geddes JR, Freemantle N, Mason J, et al. In: Cochrane Library. Oxford: Update Software.

Interventions for preventing tobacco sales to minors. (Cochrane Review, latest version 13 Jul 1999). Lancaster T, Stead LF. In: Cochrane Library. Oxford: Update Software.

Carbamazepine for schizophrenia and schizoaffective psychoses. (Cochrane Review, latest version 14 Jul 1999). Leucht S, McGrath J, White P, et al. In: Cochrane Library. Oxford: Update Software.

Brief intervention for harm reduction with alcohol-positive older adolescents in a hospital emergency department. Monti PM, Spirito A, Myers M, et al. J Consult Clin Psychol 1999 Dec;67:989-94.

Treatment of depression: newer pharmacotherapies. Mulrow CD, Williams JW Jr, Trivedi M, et al. Evidence Report/Technology Assessment no 7. AHCPR publication no. 99-E014. Rockville, MD: Agency for Health Care Policy and Research. February 1999.

A comparison of morning-only and morning/late afternoon Adderall to morning-only, twice-daily, and three times-daily methylphenidate in children with attention-deficit/hyperactivity disorder. Pelham WE, Gnagy EM, Chronis AM, et al. Pediatrics 1999 Dec;106:1300-11.

\section{Diagnosis}

Validation of the Chinese-Cantonese version of the Hospital Anxiety and Depression Scale and comparison with the Hamilton Rating Scale of Depression. Leung CM, Wing YK, Kwong PK, et al.Acta Psychiatr Scand 1999 Dec;100:456-61.

Co-occurring severe mental illness and substance use disorders: a review of recent research. RachBeisel J, Scott J, Dixon L. Psychiatr Serv 1999 Nov;50:1427-34.
Validation and utility of a self-report version of PRIME-MD: the PHQ Primary Care Study. Spitzer RL, Kroenke K, Williams JBW, and the Patient Health Questionnaire Primary Care Study Group. JAMA 1999 Nov 10;282:1737-44.

\section{Prognosis}

Minor and major depression and the risk of death in older persons. Penninx BWJH, Geerlings SW, Deeg DJH, et al. Arch Gen Psychiatry 1999 Oct;56:889-95.

\section{Aetiology}

Hyperactivity and reading disability: a longitudinal study of the nature of the association. Chadwick $\mathrm{O}$, Taylor $\mathrm{E}$, Taylor A, et al.J Child Psychol Psychiatry 1999 Oct;40:1039-50.

Exploring the dose-response relationship between alcohol consumption and the risk of several alcohol-related conditions: a meta-analysis. Corrao G, Bagnardi V, Zambon A, et al. Addiction 1999 Oct;94:1551-73.

Charting the relationship trajectories of aggressive, withdrawn, and aggressive/withdrawn children during early grade school. Ladd GW, Burgess KB. Child Dev 1999 Jul-Aug;70:910-29.

Boys who join gangs: a prospective study of predictors of first gang entry. Lahey BB, Gordon RA, Loeber R, et al.J Abnorm Child Psychol 1999 Aug;27:261-76.

Naturalistic weight-reduction efforts prospectively predict growth in relative weight and onset of obesity among female adolescents. Stice E, Cameron RP, Killen JD, et al.J Consult Clin Psychol 1999 Dec;67:967-74.

Childhood victimization and drug abuse: a comparison of prospective and retrospective findings. Widom CS, Weiler BL, Cottler LB. J Consult Clin Psychol 1999 Dec;67:867-80.

\section{Qualitative}

Towards recovery: living in a home-like setting after the move from a hospital ward. Pejlert A, Asplund K, Norberg A.J Clin Nurs 1999 Nov;8:663-74.

\section{Correction}

In the August 1998 issue of Evidence-Based Mental Health, 2 errors were detected in the abstract for the article by Gloaguen et al (p 76). In the main results section of the abstract, we indicate that there was no significant heterogeneity in the results of studies comparing cognitive therapy (CT) $v$ other therapies when in fact there was. Furthermore, we indicate that there was significant heterogeneity in the results of studies comparing CT $v$ behaviour therapy when in fact there was not. 